\title{
Is it time to take a new tack toward an old adversary?
}

\author{
Thoralf M. Sundt, MD
}

\author{
From the Division of Cardiac Surgery, Massachusetts General Hospital; and the Department of Surgery, Harvard \\ Medical School, Boston, Mass. \\ Disclosures: Author has nothing to disclose with regard to commercial support. \\ Received for publication March 14, 2017; accepted for publication March 17, 2017; available ahead of print April \\ $19,2017$. \\ Address for reprints: Thoralf M. Sundt, MD, Division of Cardiac Surgery, Massachusetts General Hospital, 55 \\ Fruit S, Boston, MA 02114 (E-mail: tsundt@mgh.harvard.edu). \\ J Thorac Cardiovasc Surg 2017; 154:97 \\ $0022-5223 / \$ 36.00$ \\ Copyright (C) 2017 by The American Association for Thoracic Surgery \\ http://dx.doi.org/10.1016/j.jtcvs.2017.03.070
}

In their article in this issue of the Journal, Nishida and colleagues ${ }^{1}$ present an important clinical series of patients treated for acute dissection. It is a valuable data set for (at least) 3 reasons: it is a large series of patients treated for an uncommon condition, the follow-up is quite long at a mean of 7 years and complete at $94 \%$, and the patients were treated in a systematic manner.

Nishida and colleagues ${ }^{1}$ set up the operating room as soon as they are made aware of the patient and preferentially admit patients directly to the operating theater. The surgical approach was standardized preferentially to femoral inflow absent a shaggy aorta, with transition to apical inflow if there was collapse of the true lumen. Most often, Nishida and colleagues ${ }^{1}$ crossclamp the aorta during cooling while monitoring bilateral radial artery pressures to address the proximal aorta, perform the distal anastomosis as a hemiarch under circulatory arrest at $25^{\circ} \mathrm{C}$ with retrograde cerebral perfusion, and institute antegrade reperfusion. Total arch replacement is performed when the entry tear is in the arch or if the arch is aneurysmal and is supported with antegrade cerebral perfusion. Root replacement is performed when the root exceeds $4.5 \mathrm{~cm}$ or is dissected.

The reader may or may not agree with the technical approach of the authors. ${ }^{1}$ Some may prefer femoral artery inflow while others do not; some may argue for a more aggressive posture toward arch replacement or root intervention. The literature is full of such back and forth, with as yet no definitive proof and often a call for a randomized, controlled trial. Such a trial, however, cannot and will not ever be performed, at least not in the Western world, where surgical centers are many and the subjects few. In other countries, the converse may be the case, but the delay in treatment is such that the condition being treated is more appropriately considered subacute. The only data to which we can turn, then, are clinical series such as this, most often examined in retrospect and subject to all the vagaries in treatment determined by individual "surgeon preference" but exhibiting the strength of a "real-world" patient population. garbage out."

\section{References} 2017; 154:89-96.

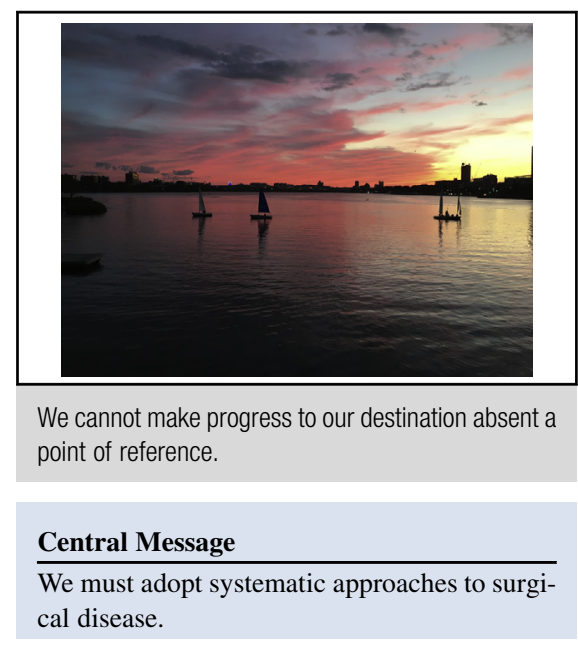

See Article page 89.

So what makes this study so interesting_at least to me? It is the disciplined application of a systematic approach to the condition. By adhering to a consistent methodology, Nishida and colleagues ${ }^{1}$ like the University of Pennsylvania group before them ${ }^{2}$ provide us a solid point of reference from which to examine alternatives. This is in marked contrast to the more typical retrospective series, in which we try to make sense of data contaminated by treatment biases often hidden even from the investigators. No amount of statistical gymnastics can overcome "garbage in,

If we are to make progress in the treatment of this vexing and lethal condition, we need more data just like those presented here. Despite the surgical proclivity to "make it up on the fly" or to "do it my way," we need to pick a protocol and stick with it for long enough to see what works. In the meantime, the establishment of clear and unambiguous protocols may help us overcome the equally daunting challenge-in North America at least_-of mortalities varying by a factor of nearly 2 between high-volume ( $\geq 5$ patients/ y) and low-volume ( $<1$ patient/y) dissection surgeons. ${ }^{3}$

1. Nishida H, Tabata M, Fukui T, Sato Y, Kin H, Takanashi S. A systematic approach to improve the outcomes of type A aortic dissection. J Thorac Cardiovasc Surg.

2. Bavaria JE, Pochettino A, Brinster DR, Gorman RC, McGarvey ML, Gorman JH, et al. New paradigms and improved results for the surgical treatment of acute type A dissection. Ann Surg. 2001;234:336-42; discussion 342-3.

3. Chikwe J, Cavallaro P, Itagaki S, Seigerman M, Diluozzo G, Adams DH. Nationa outcomes in acute aortic dissection: influence of surgeon and institutional volume on operative mortality. Ann Thorac Surg. 2013;95:1563-9. 